\title{
A quest to increase safety of anesthetics by advancements in anesthesia monitoring: scientometric analysis
}

This article was published in the following Dove Press journal:

Drug Design, Development and Therapy

II May 2015

Number of times this article has been viewed

\section{Kamen V Vlassakov Igor Kissin}

Department of Anesthesiology, Perioperative and Pain Medicine, Brigham and Women's Hospital, Harvard Medical School, Boston, MA, USA
Correspondence: Igor Kissin

Department of Anesthesiology, Brigham and Women's Hospital, 75 Francis Street, Boston, MA 021।5, USA

Tel +l 6177325052

Fax +I 6177340682

Email kissin@zeus.bwh.harvard.edu
Abstract: The aim of this study was to assess progress in the field of anesthesia monitoring over the past 40 years using scientometric analysis. The following scientometric indexes were used: popularity indexes (general and specific), representing the proportion of articles on either a topic relative to all articles in the field of anesthetics (general popularity index, GPI) or the subfield of anesthesia monitoring (specific popularity index, SPI); index of change (IC), representing the degree of growth in publications on a topic from one period to the next; and index of expectations (IE), representing the ratio of the number of articles on a topic in the top 20 journals relative to the number of articles in all $(>5,000)$ biomedical journals covered by PubMed. Publications on 33 anesthesia-monitoring topics were assessed. Our analysis showed that over the past 40 years, the rate of rise in the number of articles on anesthesia monitoring was exponential, with an increase of more than eleven-fold, from 296 articles over the 5-year period 1974-1978 to 3,394 articles for 2009-2013. This rise profoundly exceeded the rate of rise of the number of articles on general anesthetics. The difference was especially evident with the comparison of the related GPIs: stable growth of the GPI for anesthesia monitoring vs constant decline in the GPI for general anesthetics. By the 2009-2013 period, among specific monitoring topics introduced after 1980, the SPI index had a meaningful magnitude $(\geq 1.5)$ in 9 of 24 topics: Bispectral Index (7.8), Transesophageal Echocardiography (4.2), Electromyography (2.8), Pulse Oximetry (2.4), Entropy (2.3), Train-of-four (2.3), Capnography (1.9), Pulse Contour (1.9), and Electrical Nerve Stimulation for neuromuscular monitoring (1.6). Only one of these topics (Pulse Contour) demonstrated (in 2009-2013) high values for both IC and IE indexes (76 and 16.9, respectively), indicating significant recent progress. We suggest that rapid growth in the field of anesthetic monitoring was one of the most important developments to compensate for the intrinsically low margins of safety of anesthetic agents.

Keywords: anesthesia-related morbidity, anesthesia-related mortality, anesthetics, general anesthesia, regional anesthesia

\section{Introduction}

Though all classes of anesthetics have low margins of safety, they are especially low with inhalational anesthetics. As indicated in Goodman and Gilman's The Pharmacological Basis of Therapeutics, "the inhalational anesthetics have therapeutic indices $\left(\mathrm{LD}_{50} / \mathrm{ED}_{50}\right)$ that range from 2 to 4 , making these among the most dangerous drugs in clinical use." A previous analysis showed that major efforts to improve the safety margins of these agents have yielded sparse results. ${ }^{2}$ Meanwhile, anesthesia-related mortality over the past 40 years has dramatically decreased. For example, according to one of the studies in this field, the mortality solely attributable to anesthesia decreased from 357 (95\% confidence interval [CI]: 324-394) per million (pre-1970s) 
to 34 (95\% CI: 29-39) per million (1990s-2000s), ${ }^{3}$ despite a steady increase of patient risk status over the same decades. If new, safer drugs are not the major reason for this significant decline in anesthesia-related mortality, other reasons might be improvements in the techniques of anesthetic administration. However, a related analysis of scientometric indexes over the past 40 years did not identify new techniques of anesthetics administration that could have explained such a dramatic decrease in mortality. ${ }^{2}$ The aim of this study was to assess progress in the field of anesthesia monitoring that could have played an important role in the improvement of anesthetic safety. The assessment was performed with the use of scientometric indexes. In addition, we explored a possible connection between the perceived safety of anesthetic interventions and associated anesthesia monitoring: the lower the perceived safety, the greater was the frequency of monitoring as a topic in the relevant literature.

\section{Methods}

Progress in the field of anesthesia monitoring was assessed with the use of scientometric indexes. Such assessments of various classes of drugs using these indexes have been reported in a number of publications. ${ }^{4-9}$ The following four indexes were used.

\section{General popularity index}

GPI is the percentage of articles on a specific topic among all articles on anesthetics (medical subject headings [MeSH] term: Anesthetics) published over the same 5-year (or 10-year) period.

\section{Specific popularity index}

SPI is the number of articles on a specific topic within anesthesia monitoring, presented as the percentage of articles on all topics on anesthesia monitoring published over the same 5-year period.

\section{Index of change}

IC is the percentage change in the number of articles on a topic during a 5-year (or 10-year) period compared with the previous similar period. An index value $\geq 50$ was selected to represent a specific threshold value. It reflects the change in general interest in a topic.

\section{Index of expectations}

IE, or Top Journal Selectivity Index, is the ratio of the number of all types of articles on a particular topic in the top 20 journals - relative to the number of articles in all $(>5,000)$ biomedical journals covered by PubMed over 5 years, reflecting the level of interest in the top journals. An index value $\geq 10$ was selected to represent high expectations. The 20 top journals were selected based on two factors, ie, their rank sorted by impact factor, as indicated by Journal Citation Report for 2013, and the journal specialty area. They included pharmacology, anesthesia, pain, and surgery (ten journals), and general biomedical journals (also ten journals), as follows: Anesthesiology, Annals of Internal Medicine, Annals of Surgery, British Journal of Anaesthesia, British Journal of Surgery, British Medical Journal, Intensive Care Medicine, Journal of American College of Surgeons, Journal of American Medical Association, Journal of Clinical Investigation, Journal of Pharmacology and Experimental Therapeutics, The Lancet, Nature, Nature Medicine, Nature Reviews Drug Discovery, New England Journal of Medicine, Pain, Proceedings of the National Academy of Science of the United States of America, Science, and Surgery.

The articles were counted using the National Library of Medicine's PubMed Web site (http://www.ncbi.nlm.nih. gov/pubmed), which covers $>21$ million journal articles in biomedicine. Various terms related to anesthesia monitoring were entered in the search box. Filter for languages (English) was used, all types of articles were considered, and the topics were selected from various sources. ${ }^{10-15}$

The following 35 topics were searched (MeSH terms in this list are shown with capital letters): acceleromyography AND anesthesia monitoring; Arterial Pressure AND anesthesia monitoring; "bispectral index" AND anesthesia monitoring; Body Temperature AND anesthesia monitoring; Cardiac Output AND anesthesia monitoring; Cardiography, Impedance, AND anesthesia monitoring; Capnography AND anesthesia monitoring; Catheterization, Swan-Ganz, AND anesthesia monitoring; Central Venous Pressure AND anesthesia monitoring; "cerebral oximetry" AND anesthesia monitoring; Electroencephalography AND anesthesia monitoring; Echocardiography, Transesophageal, AND anesthesia monitoring; Electrical Stimulation AND neuromuscular monitoring; Electrocardiography AND anesthesia monitoring; Electromyography AND anesthesia monitoring; entropy AND anesthesia monitoring; "end-tidal concentration" AND Anesthetics; Inhalation AND anesthesia monitoring; Fluid Therapy AND goal-directed AND Anesthesia; Heart Rate AND anesthesia monitoring; "inspiratory pressure" AND anesthesia monitoring; Kinemyography AND anesthesia monitoring; mechanomyography AND anesthesia monitoring; Narcotrend AND anesthesia monitoring; Neuromuscular Monitoring AND anesthesia monitoring; Phonomyography 
AND anesthesia monitoring; ("pulse contour" OR "pulse pressure") AND anesthesia monitoring; "pulse oximetry" AND anesthesia monitoring; Respiratory Rate AND anesthesia monitoring; SEDline AND anesthesia monitoring; SNAP II AND anesthesia monitoring; "spectral edge frequency" AND anesthesia monitoring; train-of-four AND anesthesia monitoring; Ultrasonography, Doppler, AND anesthesia monitoring; "ventilation monitoring" AND Anesthesia.

The criterion for the selection of a particular topic for analysis with the use of scientometric indexes was $>50$ articles on that topic in the period 2009-2013.

To reveal a possible connection between the perceived safety of a specific type of anesthesia and associated monitoring, we compared the SPI for anesthesia monitoring with general or regional anesthesia (Anesthesia, General [MeSH term] or Anesthesia, Regional [MeSH term], respectively) to SPI for Mortality [MeSH term] or Morbidity [MeSH term] with these types of anesthesia. In addition to morbidity, we also included in these comparisons Heart Arrest [MeSH term] and Respiratory Insufficiency [MeSH term] as the most typical and serious forms of morbidity in anesthesia. We expected higher SPI for monitoring with types of anesthesia perceived as more dangerous.

\section{Results}

Of the 35 topics on anesthesia monitoring included in the search, the 33 that had at least one publication in 2009-2013 are presented in Tables 1 and 2. Figure 1 presents the 5-year publication growth for the general topic of anesthesia monitoring. The growth was exponential, with an increase of more than eleven fold, from 296 articles over 1974-1978 to 3,394 articles over 2009-2013. To put the degree of growth in publications on anesthesia monitoring into context, it was compared with the growth of publications in the field of general anesthetics (Anesthetics, General [MeSH term]).

Table I Number of 2009-20I3 articles on general topics of anesthesia monitoring introduced before 1980

\begin{tabular}{lll}
\hline $\mathbf{N}$ & Topic search terms & $\begin{array}{l}\text { Number } \\
\text { of articles }\end{array}$ \\
\hline I & Arterial pressure AND anesthesia monitoring & 413 \\
2 & Heart rate AND anesthesia monitoring & 393 \\
3 & Electroencephalography AND anesthesia monitoring & 332 \\
4 & Cardiac output AND anesthesia monitoring & 271 \\
5 & Neuromuscular monitoring AND anesthesia & 218 \\
6 & Electrocardiography AND anesthesia monitoring & 145 \\
7 & Respiratory rate AND anesthesia monitoring & 132 \\
8 & Central venous pressure AND anesthesia monitoring & 103 \\
9 & Body temperature AND anesthesia monitoring & 83 \\
\hline
\end{tabular}

Figure 2 illustrates the 10-year changes of GPI (the share of articles on each of these two topics relative to all articles on Anesthetics [MeSH term]) presented as a percentage of GPI on the same topic over the previous 10 years. The figure indicates that over the three 10-year periods, changes in GPI for anesthesia monitoring were always positive, and changes in GPI for general anesthetics were always negative. This difference was especially significant in the period 1984-1993: GPI for anesthesia monitoring increased by $77 \%$ and for general anesthesia decreased by $26 \%$. The rapid growth of publications on anesthesia monitoring was associated with the introduction of many new methods of monitoring over the past 40 years. Figure 1 indicates (arrows) the approximate time of the introduction of some of the methods of monitoring (based on the initial growth in publications on a topic).

The general topics of anesthesia monitoring introduced before 1980 are presented in Table 1. In 2009-2013, the number of articles on some of these topics was rather high, reaching 413 and 393 on arterial pressure (AND anesthesia monitoring) and heart rate (AND anesthesia monitoring), respectively. Table 2 presents specific topics of anesthesia monitoring introduced after 1980. In 2009-2013, only ten of these topics had more than 50 articles. The most popular of them is the topic related to bispectral index (263 articles). The growth of publications on various specific topics within anesthesia monitoring is quite different even in the very beginning of a topic development. This is evident in Table 3, which presents the time periods from the publication of the 10th to the 100th article on the related topics: the difference varies from 4 years to 21 years. The most rapid growth was with bispectral index and pulse oximetry (4 years and 6 years, respectively), and the least rapid development was with Central Venous Pressure (21 years) and Swan-Ganz Catheter (30 years).

Scientometric indexes (SPI, IC, and IE) were determined when the number of articles on a specific monitoring topic was $\geq 50$ in 2009-2013. They are presented in Table 4 . SPI is the most impressive with bispectral index (7.8 in 2009-2013). The next most popular topic is transesophageal echocardiography (4.2 in 2009-2013). The time course of SPI during the extended period of time is presented in Figures 3 and 4 . Figure 3 presents some of the general topics within anesthesia monitoring. It indicates that SPI for most important topics did not change much from 1974-1978 to 2009-2013, especially with heart rate monitoring or neuromuscular monitoring in anesthesia. Figure 4 presents some of the specific topics of anesthesia monitoring introduced after 1980. It demonstrates the dramatic rises in bispectral index and tranesophageal 
Table 2 Number of 2009-20I3 articles on specific topics of anesthesia monitoring introduced after 1980

\begin{tabular}{lll}
\hline $\mathbf{N}$ & Topic search terms & Number of articles \\
\hline 1 & "Bispectral index" AND anesthesia monitoring' & 263 \\
2 & Echocardiography, Transesophageal, AND anesthesia monitoring & 141 \\
3 & Electromyography AND anesthesia monitoring & 94 \\
4 & "Pulse oximetry" AND anesthesia monitoring & 82 \\
5 & Entropy AND anesthesia monitoring & 79 \\
6 & Train-of-four AND anesthesia monitoring & 77 \\
7 & Ultrasonography, Doppler, AND anesthesia monitoring & 76 \\
8 & Capnography AND anesthesia monitoring & 66 \\
9 & ("Pulse contour" OR "pulse pressure") AND anesthesia monitoring & 65 \\
10 & Electrical stimulation AND neuromuscular monitoring & 54 \\
11 & Fluid therapy AND goal-directed AND Anesthesia & 48 \\
12 & Acceleromyography AND anesthesia monitoring & 33 \\
13 & "Cerebral oximetry" AND anesthesia monitoring & 30 \\
14 & Catheterization, Swan-Ganz, AND anesthesia monitoring & 29 \\
15 & "End-tidal concentration" AND Anesthetics, Inhalation AND anesthesia monitoring & 14 \\
16 & Narcotrend AND anesthesia monitoring & 13 \\
17 & "Spectral edge frequency" AND anesthesia monitoring & $<10$ \\
18 & Mechanomyography AND anesthesia monitoring & $<10$ \\
19 & Cardiography, Impedance, AND anesthesia monitoring & $<10$ \\
20 & Kinemyography AND anesthesia monitoring & $<10$ \\
21 & Phonomyography AND anesthesia monitoring & $<10$ \\
22 & SEDline AND anesthesia monitoring & $<10$ \\
23 & SNAP II AND anesthesia monitoring & $<10$
\end{tabular}

echocardiography. As far as SPI of pulse oximetry is concerned, its peak was in 1989-1993; after this period, its SPI began to decline.

Two other indexes (IC and IE) demonstrate (back to Table 4) significant progress only with pulse contour monitoring: in
2009-2013, the IC was 76 and IE was 16.9. It is of interest that in two areas of monitoring having a long history - neuromuscular monitoring (electromyography, train-of-four, and electrical nerve stimulation) and processed electroencephalography (bispectral index and entropy) - the IE in 2009-2013 continued

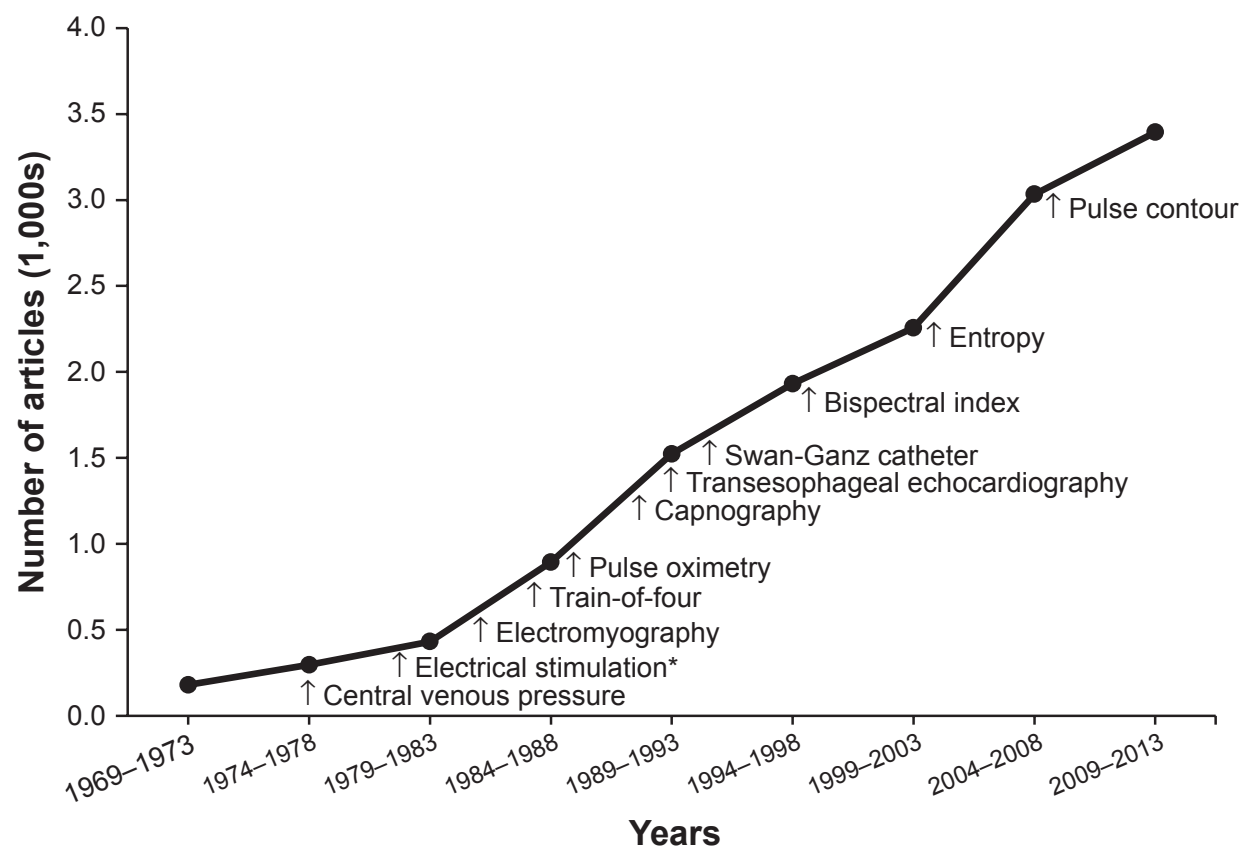

Figure I Five-year growth of all articles on anesthesia monitoring.

Notes: ${ }^{\uparrow}$ Indicates the time of initial growth in publications on a related specific topic of anesthesia monitoring. *Indicates the topic of electrical nerve stimulation for neuromuscular monitoring. 


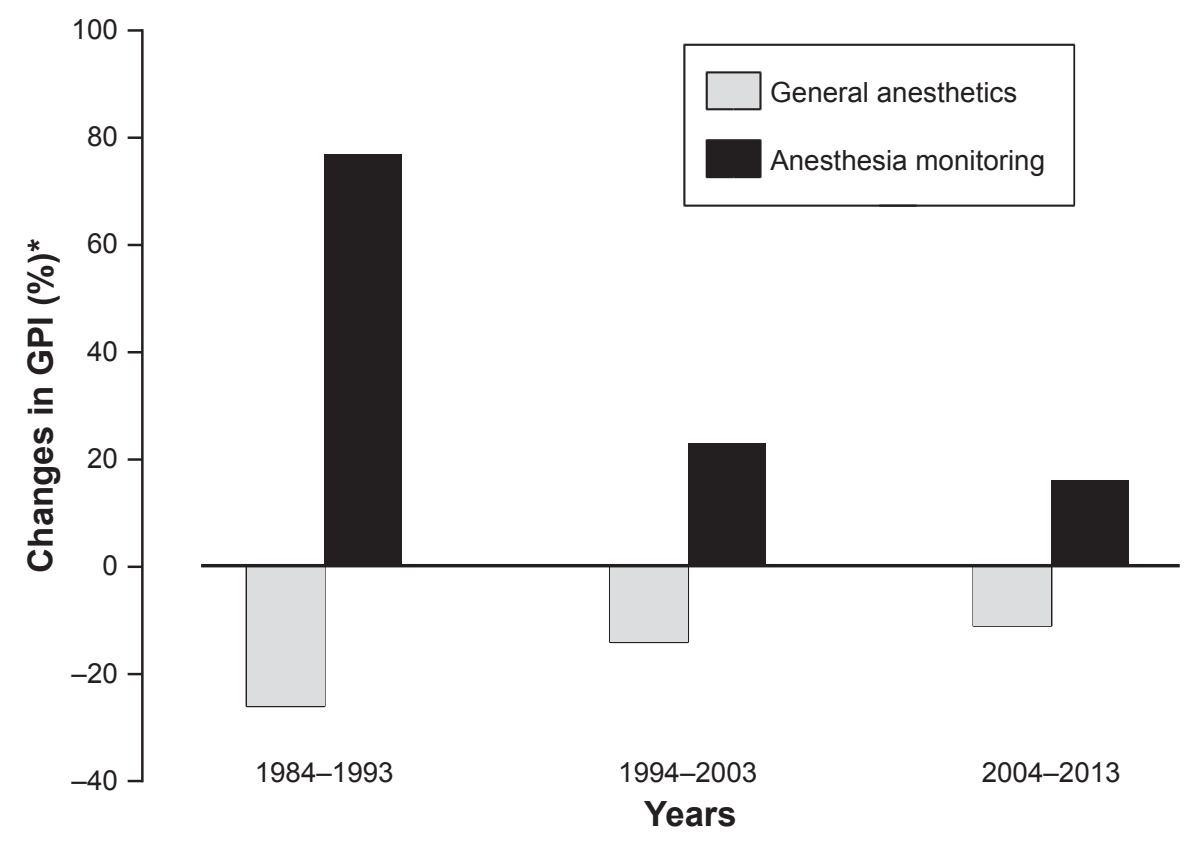

Figure 2 Ten-year changes* of GPI for two fields of publications: general anesthetics and anesthesia monitoring.

Notes: GPI represents the share of articles in a field relative to all articles on anesthetics during a I0-year period. *Compared to GPI for the same field over the previous I0 years. Abbreviation: GPI, general popularity index.

to be high $(>10$ or even $>20)$. On the other hand, in 2009-2013, the IE for transesophageal echocardiography was only 5.0 (a profound decline from 24.3 in 1999-2003).

Table 5 presents our data on the possible connection between the perceived safety of general (vs regional) anesthesia and its association with the topic of anesthesia monitoring. It indicates that the combined general anesthesia-anesthesia monitoring SPI (a percentage of articles on general anesthesia that also has the associated term of anesthesia monitoring) was 4.7. At the same time, the combined regional anesthesiaanesthesia monitoring SPI was 2.7 (57\% of the SPI for combined general anesthesia-anesthesia monitoring). It is of interest that the combined general anesthesia-mortality SPI was 7.3, and the regional anesthesia-mortality SPI was 3.9
( $53 \%$ of the SPI for combined general anesthesia-mortality), a decrease almost identical to that seen with anesthesia monitoring. With topics on morbidity, heart arrest, and respiratory insufficiency, SPIs with regional anesthesia were also lower than those with general anesthesia.

\section{Discussion}

The results presented here indicate that over the past 40 years, there was a more than eleven-fold increase in the number of articles on anesthesia monitoring. The rise of publications in the subfield of monitoring, if presented as the share of all articles in the broad field of anesthesia, was in stark contrast to the decline in the subfield of general anesthetics. The previous scientometric assessment of the field of anesthetic

Table 3 Time periods from publication of the 10th to the 100th article on related topics in anesthesia monitoring

\begin{tabular}{llll}
\hline Topic & Year of I0th article & Year of I 00th article & Difference (number of years) \\
\hline Central venous pressure & 1974 & 1995 & 21 \\
Electrical nerve stimulation for & 1981 & 1995 & \\
neuromuscular monitoring & & 1995 & 14 \\
Electromyography & 1981 & 1997 & 14 \\
Train-of-four & 1985 & 1993 & 6 \\
Pulse oximetry & 1987 & 2002 & 20 \\
Capnography & 1989 & 2012 & 2002 \\
Swan-Ganz catheter & 1992 & 2010 & 8 \\
Bispectral index & 1998 & 2013 \\
Entropy & 2002 & & 8 \\
Pulse contour & 2005 & & 8 \\
\hline
\end{tabular}




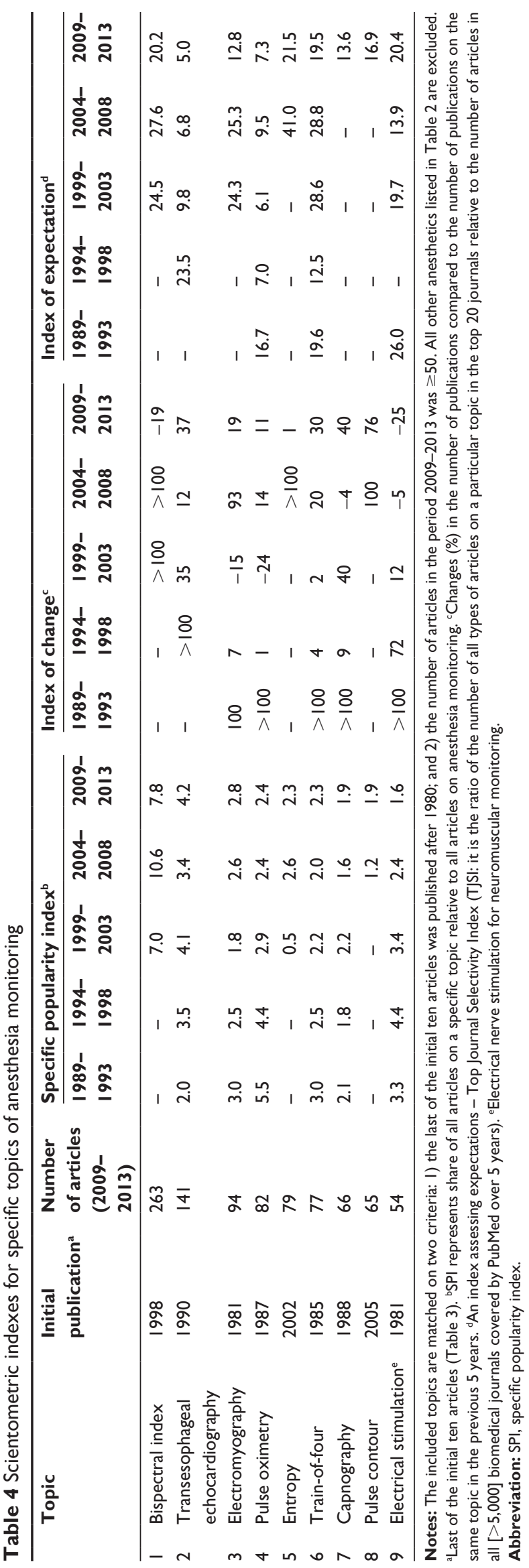

drugs concluded that over a period of 30-40 years, there had been no new anesthetics indicating real progress in terms of increased safety margins. ${ }^{2}$ Despite this, anesthesia mortality over the past 40 years has dramatically decreased., ${ }^{3,16-21}$ At the same time, the risk status of patients presenting for surgery, expressed by the validated American Society of Anesthesiologists (ASA) score, has increased. In addition, the number of surgeries with higher requirements for patient safety (open heart surgery) has also dramatically increased. Therefore, one of the possible reasons for the increased safety of anesthesia could be the rapid development of anesthesia monitoring.

Some of the methods of anesthesia monitoring were introduced long before the time of the dramatic decrease in anesthesia mortality. As seen in Figure 1, the popularity of heart rate or arterial pressure monitoring did not change much between the periods 2009-2013 and 1974-1978. The introduction of only one type of monitoring coincided with the time of change in anesthesia mortality - the monitoring of neuromuscular blockade. It is peculiar that the introduction (in the 1940s) of neuromuscular blocking agents as anesthetic adjuncts was one of the most important steps to compensate - at least to some extent - for the low safety margins of anesthetics: with muscle relaxation no longer dependent on the use of high doses of general anesthetics, the danger of being too close to the limits of their safety margins is reduced. However, very soon, it was discovered that the administration of neuromuscular blocking agents requires myorelaxation monitoring. As reported in 1954, the use of curare in anesthesia led to a nearly six-fold increase in postoperative complications and deaths. ${ }^{16}$ The profound reduction of anesthesia-related mortality between the pre1970s period and the 1970s-1980s (from 357 [95\% CI: 324-394] per million to 52 [95\% CI: 42-64] per million; Table 6) coincides with the development of neuromuscular monitoring: electrical nerve stimulation, train-of-four, and electromyography (Figure 1). Although the importance of neuromuscular blockade monitoring became obvious long ago, quantitative monitoring - particularly for managing reversal of neuromuscular blockade - is still not in widespread use. ${ }^{22}$ Thus, neuromuscular monitoring might remain an important reserve for the additional reduction of anesthesia mortality and morbidity. The importance of this problem probably explains the unusually stable high values of the IE indexes for topics associated with neuromuscular monitoring: electrical nerve stimulation - 26.0 in 1989-1993 and still 20.4 in 2009-2013; train-of-four - 19.6 in 1989-1993 and 19.5 in 2009-2013 (Table 4). 


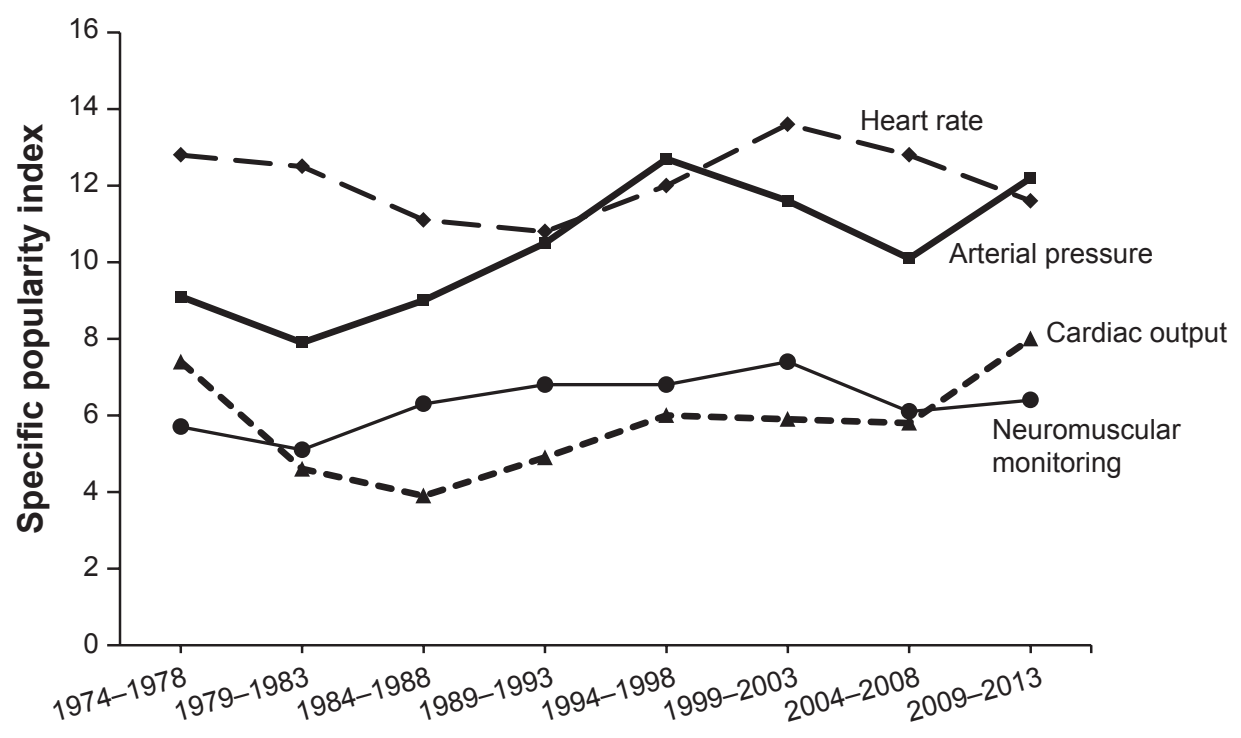

Years

Figure 3 General topics of anesthesia monitoring introduced before 1980.

Note: SPI represents the share of articles on a topic relative to all articles on anesthesia monitoring during a 5-year period.

Abbreviation: SPI, specific popularity index.

Transesophageal echocardiography is a highly popular monitoring technique, as reflected by the high SPI. However, in contrast to the topics related to neuromuscular monitoring, the IE index of echocardiography declined from 23.5 in 1994-1998 to 5.0 in 2009-2013. Could this be due to the fact that ultrasonography has long been widely used in many areas of medicine (in obstetrics, it appeared to boom since 1966)?

The only monitoring technique demonstrating recent progress is pulse contour (pulse pressure) monitoring: in
2009-2013, the IE and IC values with this technique were high -16.9 and 76 , respectively.

The processed electroencephalogram monitors (bispectral index, entropy, and Narcotrend) occupy a unique position among anesthesia monitoring techniques. Although first suggested in $1937,{ }^{23}$ electroencephalographic monitors were not commonly used in anesthetic practice until introduction of the bispectral index. ${ }^{24}$ These monitors are mostly used to prevent intraoperative awareness. ${ }^{25}$ The concepts underlying

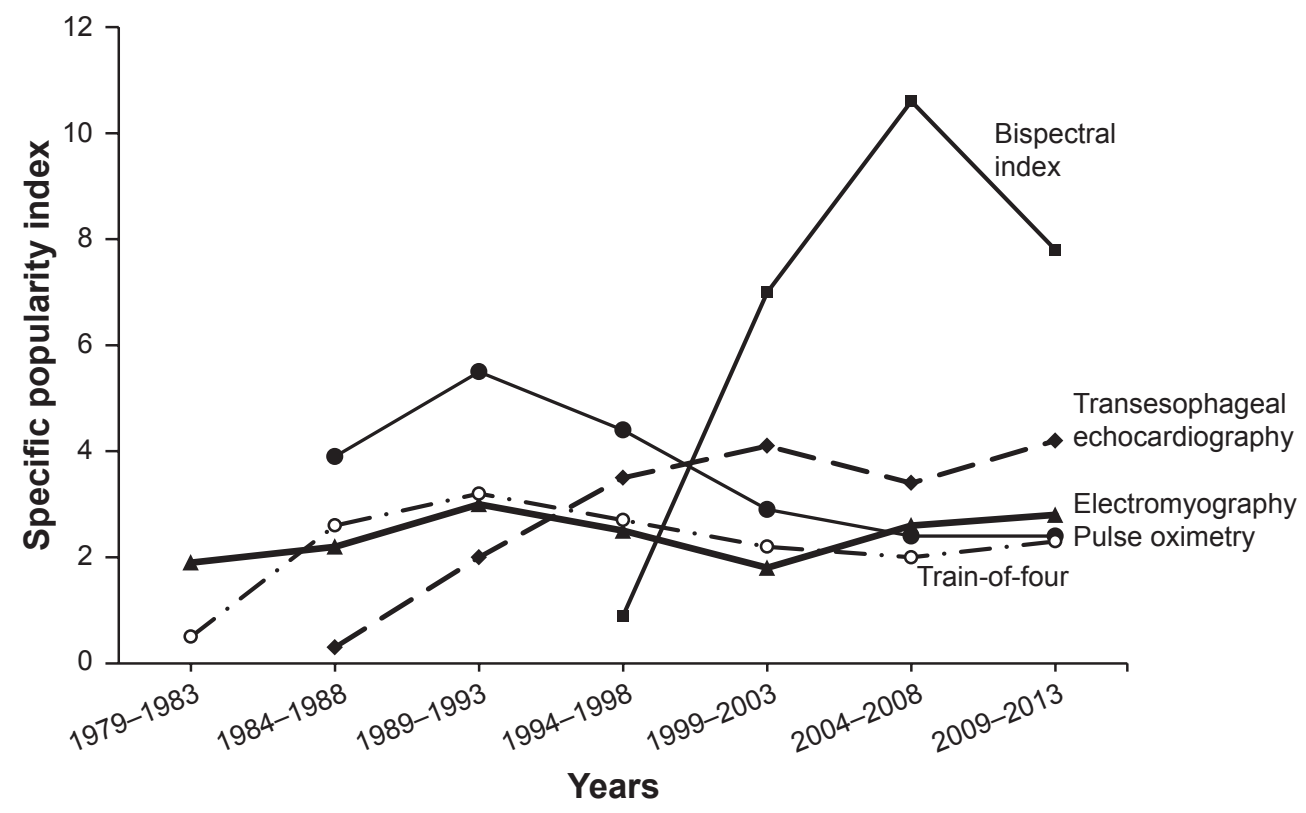

Figure 4 Most prominent specific topics of anesthesia monitoring introduced after 1980.

Note: SPI represents the share of articles on a topic relative to all articles on anesthesia monitoring during a 5-year period. Abbreviation: SPI, specific popularity index. 
Table 5 Perceived safety of general vs regional anesthesia by their association with SPI of anesthesia monitoring

\begin{tabular}{|c|c|c|c|c|c|c|c|}
\hline \multirow[t]{2}{*}{ Main topic } & \multicolumn{3}{|c|}{ General anesthesia } & \multicolumn{4}{|c|}{ Regional anesthesia } \\
\hline & $\begin{array}{l}\text { General } \\
\text { anesthesia } \\
\text { only }\end{array}$ & $\begin{array}{l}\text { Main topic } \\
\text { and general } \\
\text { anesthesia }\end{array}$ & SPI* & $\begin{array}{l}\text { Regional } \\
\text { anesthesia } \\
\text { only }\end{array}$ & $\begin{array}{l}\text { Main topic } \\
\text { and regional } \\
\text { anesthesia }\end{array}$ & SPI* & $\begin{array}{l}\text { As percentage } \\
\text { of SPI for general } \\
\text { anesthesia }\end{array}$ \\
\hline Anesthesia monitoring & $10,998^{+}$ & 516 & 4.7 & $8,109^{+}$ & 221 & 2.7 & 57 \\
\hline Mortality & $10,998^{+}$ & 798 & 7.3 & $8,109^{+}$ & 319 & 3.9 & 53 \\
\hline Morbidity & $10,998^{+}$ & $|, 53|$ & 13.9 & $8,109^{+}$ & 782 & 9.6 & 69 \\
\hline Heart arrest & $10,998^{+}$ & 102 & 0.9 & $8,109^{+}$ & 53 & 0.6 & 67 \\
\hline Respiratory insufficiency & $10,998^{+}$ & 204 & 1.8 & $8,109^{+}$ & 56 & 0.7 & 39 \\
\hline
\end{tabular}

Notes: ${ }^{+}$Number of articles in the 2009-20I3 period. *SPI indicates the number of articles on a main topic relative to all articles on general anesthesia or regional anesthesia, respectively. Bold values indicate the most important outcome.

Abbreviation: SPI, specific popularity index.

their use are directly related to the basic understanding of general anesthetic action, the theory of which has not yet been formulated. ${ }^{26}$ It is not even clear what components of general anesthesia are reflected by the various algorithms suggested for processed electroencephalography. ${ }^{27-30}$ The close relationship of bispectral index or entropy monitoring techniques and the most important (and still controversial) concepts of general anesthetic action place these monitoring topics in prominent positions. This is probably the reason for their high IE values even when the IC values are low. For example, in 2009-2013, the IE value for bispectral index was 20.2, at a time when its IC value was actually negative (-19). A similar situation was found with entropy: in 2009-2013, its IE was 21.5 and IC - only 1.

It is of interest that perceived safety of the type of anesthesia is associated with the use of anesthesia monitoring as a topic in literature: the lower the perceived safety, the greater is the association with the topic of anesthesia monitoring. Table 5 indicates that the topic of anesthesia monitoring was less frequently associated with the topic of regional anesthesia than with general anesthesia (the difference was approximately one third). The anesthesia-related mortality coincidentally is lower with regional than with general anesthesia (according to some studies, by about a third). ${ }^{31-33}$

Going back to the abovementioned dramatic decrease in anesthesia mortality and the role of anesthesia monitoring, comparisons of the roles of monitoring and other factors, such as anesthesiologists' education and training, could be of interest. For example, Table 6 shows that during the pre-1970s period (when anesthesia mortality was sevenfold higher than in the 1970s-1980s), articles on anesthesia monitoring were not common. They increased almost 16 -fold during the 1970s-1980s. At the same time, the number of new certified anesthesiologists for the same period of time also almost doubled (from $15 \%$ to $27 \%$ of the present number of certified anesthesiologists). In addition, standardization and rigorous scrutiny of the quality of anesthesiology training were being introduced, the duration of general anesthesiology residency training increased, and numerous anesthesia subspecialties and respective fellowship programs came to life. There are also other factors to consider, such as the role of human factors ${ }^{34,35}$ (the ability of humans to perform necessary steps to succeed consistently in the complexity of real-world settings) or the factor of external pressure, given the constant changes in health care organizations ${ }^{36}$ etc.

Table 6 Anesthesia-related mortality vs anesthesia monitoring and training of anesthesiologists

\begin{tabular}{|c|c|c|c|c|c|c|}
\hline \multirow[t]{2}{*}{ Period } & \multicolumn{2}{|c|}{$\begin{array}{l}\text { Anesthesia mortality } \\
\text { (per million, } 95 \% \mathrm{Cl} \text { ) }\end{array}$} & \multicolumn{2}{|c|}{ Anesthesia monitoring ${ }^{\mathrm{b}}$} & \multicolumn{2}{|c|}{ Anesthesiologists' training ${ }^{c}$} \\
\hline & $\begin{array}{l}\text { Sole } \\
\text { mortality }\end{array}$ & $\begin{array}{l}\text { Contributory } \\
\text { mortality }\end{array}$ & $\begin{array}{l}\text { Number of } \\
\text { new articles }\end{array}$ & $\begin{array}{l}\text { \% of total } \\
(11,292)\end{array}$ & $\begin{array}{l}\text { Number of new } \\
\text { board certificates }\end{array}$ & $\begin{array}{l}\text { \% of total } \\
(47,053)\end{array}$ \\
\hline Pre-1970s & 357 (324-394) & $684(642-729)$ & $128^{d}$ & $1 \%$ & $6,859^{e}$ & $15 \%$ \\
\hline 1970s-1980s & $52(42-64)$ & $234(200-275)$ & 2,024 & $18 \%$ & 12,780 & $27 \%$ \\
\hline 1990s-2000s & $34(29-39)$ & $85(75-96)$ & 9,140 & $81 \%$ & 27,414 & $58 \%$ \\
\hline
\end{tabular}

Notes: a Mortality in developed countries solely attributable to anesthesia across a mixed surgical population who had undergone general anesthesia. ${ }^{3}$ Number of articles published during the indicated periods. 'Number of American Board of Anesthesiology diplomas awarded during the indicated periods, data from American Board of Medical Specialties. . $^{41}$ 1960-1969 period. ${ }^{e} 1940-1969$ period. Bold values indicate the most important changes.

Abbreviation: $\mathrm{Cl}$, confidence interval. 
The low safety margins of anesthetics, especially inhalational anesthetics, still place them among the most dangerous drugs in clinical use. ${ }^{1}$ As a result, anesthesiologists have constantly tried to improve anesthesia safety by various approaches: by coadministering different anesthetics to decrease doses of individual agents ("balanced anesthesia"), by combining anesthetics with adjuvant drugs, by advancements in anesthesia monitoring, by better training of anesthesia providers, etc. On the basis of the study of critical incidents in anesthesia, ${ }^{34}$ the Harvard Medical School Committee suggested the first standards of practice for preventing anesthesia accidents. ${ }^{37}$ In 1986, the ASA adopted and expanded this approach as a national standard. Anesthesiology was the first specialty to adopt a national standard for safety improvements. In 1986, the Anesthesia Patient Safety Foundation was organized, ${ }^{38,39}$ later followed by the National Patient Safety Foundation.

In conclusion, advancements in monitoring have become and remain one of the most important components of patient safety system in anesthesia. The search for the "Ideal Anesthetic" evolved into a search for the "Optimal Monitoring System".

\section{Disclosure}

The authors report no conflicts of interest in this work.

\section{References}

1. Patel PM, Patel HH, Roth DM. General anesthetics and therapeutic gases. In: Brunton L, Chabner BA, Knollmann BC, editors. Goodman and Gilman's Pharmacological Basis of Therapeutics. 12th ed. New York: McGraw-Hill; 2011:527-564.

2. Vlassakov KV, Kissin I. Scientometrics of anesthetic drugs and their techniques of administration, 1984-2013. Drug Des Devel Ther. 2014;8: 2463-2473.

3. Bainbridge D, Martin J, Arango M, Cheng D. Perioperative and anaesthetic-related mortality in developed and developing countries: a systematic review and meta-analysis. Lancet. 2012;380:1075-1081.

4. Kissin I. Can a bibliometric indicator predict the success of a drug? Scientometrics. 2011;86:785-795.

5. Kissin I, Bradley EL Jr. Top Journals Selectivity Index: is it acceptable for drugs beyond the field of analgesia? Scientometrics. 2011;88: 589-597.

6. Kissin I, Bradley EL Jr. Top Journal Selectivity Index and 'me-too' drugs. Scientometrics. 2012;91:131-142.

7. Kissin I. An early indicator of drug success: Top Journal Selectivity Index. Drug Des Devel Ther. 2013;7:93-98.

8. Correll DJ, Vlassakov KV, Kissin I. No evidence of real progress in treatment of acute pain, 1993-2012: scientometric analysis. J Pain Res. 2014;7:199-210.

9. Kissin I. Scientometric assessment of drugs for chronic pain, 1979-2013: rapid growth of publications, paucity of successful drugs. JPain Res. 2014; 7:505-514.

10. Miller RD, Eriksson LI, Fleisher L, Wiener-Kronish JP, Young WL, editors. Miller's Anesthesia. 7th ed. Philadelphia: Churchill Livingstone; 2010 .
11. Evers AS, Maze M, Kharasch ED, editors. Anesthetic Pharmacology. 2nd ed. Cambridge: Cambridge Univ Press; 2010.

12. Cousins MJ, Bridenbaugh PO, Carr DB, Horlocker TT, editors. Cousins and Bridenbaugh's Neural Blockade in Clinical Anesthesia and Pain Medicine. 4th ed. Philadelphia: Wolters Kluwer; 2009.

13. Fishman SM, Ballantyne JC, Rathmell JP. Bonica's Management of Pain. 4th ed. Philadelphia: Wolters Kluwer/Lippincot Williams and Wilkins; 2010

14. Brunton LL, Chabner BA, Knollmann BC, editors. Goodman and Gilman's Pharmacological Basis of Therapeutics. 12th ed. New York: McGraw Hill Medical; 2011.

15. American Pharmacists Association. Drug Information Handbook. 22nd ed. Hudson, OH: Wolters Kluwer; 2013.

16. Beecher HK, Todd DP. A study of deaths associated with anesthesia and surgery. Ann Surg. 1954;140:2-34.

17. Dornette WH, Orth OC. Death in the operating room. Curr Res Anesth Analg. 1956;35:545-569.

18. Memery HN. Anesthesia mortality in private practice. A ten-year study. JAMA. 1965;194:1185-1188.

19. Marx GF, Mateo CV, Orkin LR. Computer analysis of postanesthetic deaths. Anesthesiology. 1973;39:54-58.

20. Bodlander FM. Deaths associated with anaesthesia. Br J Anaesth. 1975; 47:36-40.

21. Fleisher LA. Risk of anesthesia. In: Miller RD, Eriksson LI, Fleisher L, Wiener-Kronish JP, Young WL, editors. Miller's Anesthesia. 7th ed. Philadelphia: Churchill Livingstone; 2010:969-999.

22. Todd MM, Hindman BJ, King BJ. The implementation of quantitative electromyographic neuromuscular monitoring in an academic anesthesia department. Anesth Analg. 2014;119:323-331.

23. Gibbs FA, Gibbs EL, Lennox WG. Effect on the electroencephalogram of certain drugs which influence nervous activity. Arch Intern Med. 1937; 60:154-166.

24. Sigl JC, Chamoun NG. An introduction to bispectral analysis for the electroencephalogram. J Clin Monit. 1994;10:392-404.

25. Avidan MS, Mashour GA. Mind the gap: attitudes towards intraoperative brain monitoring. Anesth Analg. 2014;119:1022-1025.

26. Perouansky M, Pearce RA, Hemmings HC Jr. Inhaled anesthetics: mechanism of action. In: Miller RD, Eriksson LI, Fleisher LA, Wiener Kronish JP, Young WL, editors. Miller's Anesthesia. 7th ed. Philadelphia, PA: Churchill Livingstone; 2010:515-588.

27. Gleb AW, Leslie K, Stanski DR, Shafer SL. Monitoring the depth of anesthesia. In: Miller RD, Eriksson LI, Fleisher LA, Wiener Kronish JP, Young WL, editors. Miller's Anesthesia. 7th ed. Philadelphia, PA: Churchill Livingstone; 2010:1229-1265.

28. Glass PS, Bloom M, Kearse L, Rosow C, Sebel P, Manberg P. Bispectral analysis measures sedation and memory effects of propofol, midazolam, isoflurane, and alfentanil in healthy volunteers. Anesthesiology. 1997; $86: 836-847$.

29. Kissin I. Depth of anesthesia and bispectral index monitoring. Anesth Analg. 2000;90:1114-1117.

30. Schneider G, Jordan D, Schwarz G, et al; European Multicenter EEGAEP Anesthesia Monitoring Study Group and Research Group Knowledge-based Signal Processing. Monitoring depth of anesthesia utilizing a combination of electroencephalographic and standard measures. Anesthesiology. 2014;120:819-828.

31. Bulka CM, Shotwell MS, Gupta RK, Sandberg WS, Ehrenfeld JM. Regional anesthesia, time to hospital discharge and in-hospital mortality: a propensity score matched analysis. Reg Anesth Pain Med. 2014;39:381-386.

32. Rodgers A, Walker N, Schug S, et al. Reduction of postoperative mortality and morbidity with epidural or spinal anaesthesia: results from overview of randomized trials. BMJ. 2000;321:1-12.

33. Memtsoudis SG, Sun X, Chiu Y-L, et al. Perioperative comparative effectiveness of anesthetic technique in orthopedic patients. Anesthesiology. 2013;118:1046-1058. 
34. Cooper JB, Newbower RS, Long CD, McPeek B. Preventable anesthesia mishaps: a study of human factors. Anesthesiology. 1978;49: 399-406.

35. Weinger MB, Gaba DM. Human factors engineering in patient safety. Anesthesiology. 2014;120:801-806.

36. Glance LG, Fleisher LA. Anesthesiology and health care reform: a call to action. Anesthesiology. 2014;120:257-259.

37. Eichorn JH, Cooper JB, Cullen DJ, Maier WR, Philip JH, Seeman RG. Standards for patient monitoring during anesthesia at Harvard Medical School. JAMA. 1986;256:1017-1020.
38. Stoelting RK. Apsf Foundation History; 2010. Available from: www. apsf.org/about_history.php. Accessed October 9, 2014.

39. Agarwala AV, McCarty LK, Pian-Smith MCM. Anesthesia quality and safety. Anesthesiology. 2014;120:253-256.

40. American Board of Medical Specialties (ABMS). 2012 ABMS Certificate Statistics. Chicago, IL: American Board of Medical Specialties; 2012. Available from: https://www.acep.org/uploadedFiles/ACEP/ Membership/ACEP_chapters/chapter_services/chapter_membership_ marketing/ABMS\%202012.pdf. Accessed September 10, 2014.

\section{Publish your work in this journal}

Drug Design, Development and Therapy is an international, peerreviewed open-access journal that spans the spectrum of drug design and development through to clinical applications. Clinical outcomes, patient safety, and programs for the development and effective, safe, and sustained use of medicines are a feature of the journal, which has also been accepted for indexing on PubMed Central. The manuscript management system is completely online and includes a very quick and fair peer-review system, which is all easy to use. Visit http://www.dovepress.com/testimonials.php to read real quotes from published authors.

Submit your manuscript here: http://www.dovepress.com/drug-design-development-and-therapy-journal 